SECOND EDITION

\title{
the NATURE of LEADERSHIP
}

\author{
EDITORS \\ DAVID V. DAY \\ University of Western Australia \\ JOHN ANTONAKIS \\ University of Lausanne
}

\section{(SSAGE}




\section{@SAGE}

Los Angeles | London | New Delhi

Singapore | Washington DC

FOR INFORMATION:

SAGE Publications, Inc.

2455 Teller Road

Thousand Oaks, California 91320

E-mail: order@sagepub.com

SAGE Publications Ltd.

1 Oliver's Yard

55 City Road

London EC1Y 1SP

United Kingdom

SAGE Publications India Pvt. Ltd.

B 1/I 1 Mohan Cooperative Industrial Area

Mathura Road, New Delhi 110044

India

SAGE Publications Asia-Pacific Pte. Ltd.

33 Pekin Street \#02-01

Far East Square

Singapore 048763

Acquisitions Editor: Lisa Cuevas Shaw

Editorial Assistant: MaryAnn Vail

Production Editor: Kelle Schillaci

Copy Editor: Ellen Howard

Typesetter: C\&M Digitals (P) Ltd.

Proofreader: Dennis W. Webb

Indexer: Sheila Bodell

Cover Designer: Gail Buschman

Marketing Manager: Helen Salmon

Permissions Editor: Karen Ehrmann

Copyright (C) 2012 by SAGE Publications, Inc.

All rights reserved. No part of this book may be reproduced or utilized in any form or by any means, electronic or mechanical, including photocopying, recording, or by any information storage and retrieval system, without permission in writing from the publisher.

Printed in the United States of America

Library of Congress Cataloging-in-Publication Data

The nature of leadership / editors, David V. Day, John Antonakis. - 2nd ed.

p. $\mathrm{cm}$.

Includes bibliographical references and index.

ISBN 978-1-4129-8020-3 (pbk.)

1. Leadership. I. Day, David V., 1956-

II. Antonakis, John.

HD57.7.N377 2012 658.4'092—dc22 2010054158

This book is printed on acid-free paper.

111213141510987654321 


\section{Contents}

PREFACE vii

ACKNOWLEDGMENTS ix

PART I. INTRODUCTION

Chapter 1. Leadership: Past, Present, and Future

David V. Day and John Antonakis

PART II. LEADERSHIP: SCIENCE, NATURE, AND NURTURE

Chapter 2. Aggregation Processes and Levels of Analysis as Organizing Structures for Leadership Theory

Robert G. Lord and Jessica E. Dinh

Chapter 3. Advances in Leadership Research Methods Michael J. Zyphur, Adam P. Barsky, and Zhen Zhang

Chapter 4. The Nature of Leadership Development David V. Day

Chapter 5. The Nature in Leadership: Evolutionary, Biological, and Social Neuroscience Perspectives Mark Van Vugt

\section{PART III. THE MAJOR SCHOOLS OF LEADERSHIP}

Chapter 6. Individual Differences in Leadership

Timothy A. Judge and David M. Long

Chapter 7. Contingencies, Context, Situation, and Leadership

Roya Ayman and Susan Adams

Chapter 8. Transformational and Charismatic Leadership

John Antonakis

Chapter 9. The Nature of Relational Leadership:

A Multitheoretical Lens on Leadership

Relationships and Processes

Mary Uhl-Bien, John Maslyn, and Sonia Ospina 
Chapter 10. In the Minds of Followers:

Follower-Centric Approaches to Leadership

Douglas J. Brown

Chapter 11. The Nature of Shared Leadership

Christina L. Wassenaar and Craig L. Pearce

\section{PART IV. LEADERSHIP AND SPECIAL DOMAINS}

Chapter 12. Leadership and Culture

Deanne N. Den Hartog and Marcus W. Dickson

Chapter 13. Leadership and Gender

437

Linda L. Carli and Alice H. Eagly

Chapter 14. Leadership and Identity

Daan van Knippenberg

Chapter 15. Ethics and Effectiveness:

The Nature of Good Leadership

508

Joanne B. Ciulla

PART V. CONCLUSION

Chapter 16. The Crucibles of Authentic Leadership

Warren Bennis

Author Index

Subject Index

About the Editors

589

About the Contributors 


\section{Leadership: Past, Present, and Future}

\section{David V. Day}

\section{John Antonakis}

In industrial, educational, and military settings, and in social movements, leadership plays a critical, if not the most critical, role, and is therefore an important subject for study and research.

(Bass, 2008, p. 25)

eadership matters, according to prominent leadership scholars (see also Bennis, 2007). But what is leadership? That turns out to be a challenging question to answer. Leadership is a complex and diverse topic, and trying to make sense of leadership research can be an intimidating endeavor. One comprehensive handbook of leadership (Bass, 2008), covering more than a century of scientific study, comprises more than 1,200 pages of text and more than 200 additional pages of references! There is clearly a substantial scholarly body of leadership theory and research that continues to grow each year.

Given the sheer volume of leadership scholarship that is available, our purpose is not to try to review it all. That is why our focus is on the nature or essence of leadership as we and our chapter authors see it. But to fully understand and appreciate the nature of leadership, it is essential that readers have some background knowledge of the history of leadership research, the various theoretical streams that have evolved over the years, and emerging issues that are pushing the boundaries of the leadership frontier.

Further complicating our task is that more than one hundred years of leadership research have led to several paradigm shifts and a voluminous body of knowledge. On several occasions, scholars of leadership became quite frustrated by the large amount of false starts, incremental theoretical advances, and contradictory findings. As stated more than five decades ago by Warren Bennis (1959, pp. 259-260), "Of all the hazy and confounding areas in social psychology, leadership theory undoubtedly contends for 
top nomination.... Probably more has been written and less is known about leadership than about any other topic in the behavioral sciences." In a similar vein, Richard Hackman and Ruth Wageman (2007) more recently concluded that the leadership field is "curiously unformed" (p. 43).

For those who are not aware of the various crises leadership researchers have faced, imagine taking pieces of several sets of jigsaw puzzles, mixing them, and then asking someone to put the pieces together into one cohesive picture. Analogously, leadership researchers have struggled for most of the last century to put together an integrated, theoretically cohesive view of the nature of leadership, invariably leading to disappointment in those who attempted it. Also, the puzzle itself is changing. As noted recently, leadership is an evolving construct that reflects ongoing changes in the challenges that require leadership (Day, in press). For all these reasons, there has been much dissatisfaction and pessimism in the leadership field (e.g., Greene, 1977; Schriesheim \& Kerr, 1977) — and even calls for a moratorium on leadership research (Miner, 1975).

Fortunately, a clearer picture is beginning to emerge. Leadership scholars have been re-energized by new directions in the field, and research efforts have revitalized areas previously abandoned for apparent lack of consistency in findings (e.g., leadership trait theory). Our accumulated knowledge now allows us to explain the nature (including the biological bases) of leadership, its antecedents, and consequences with some degree of confidence. This accumulated knowledge is reflected in our volume, which will provide readers with a thorough overview of leadership and its complexities, advanced methods used to study it, how it is assessed and developed, and evolutionary perspectives on the topic (see Part II). We include six major theoretical perspectives for studying leadership: individual differences, contingency, transformational and charismatic, relational, follower-centric, and shared (see Part III). We also focus on leadership and special domains such as culture, gender, identity, and ethics (see Part IV).

To provide the necessary background to understand the chapters that follow, we first acquaint readers with the concept of leadership and why leadership is necessary. Then we briefly trace the history of leadership research and examine its major schools, most of which are reviewed in our book. Our historical overview is also necessary as an organizing framework because chapter authors frequently refer to elements of the history of leadership research. We also discuss emerging issues in leadership research and how findings are being consolidated. Finally, we provide an overview of the book and a summary of each of the respective chapters.

\section{What Is Leadership?}

Leadership is one of social science's most examined phenomena. The scrutiny afforded to leadership is not surprising, given that it is a universal activity evident in humankind and in animal species (Bass, 2008). Reference to leadership is apparent throughout classical Western and Eastern writings 
with a widespread belief that leadership is vital for effective organizational and societal functioning. Nonetheless, leadership is often easy to identify in practice but it is difficult to define precisely. Given the complex nature of leadership, a specific and widely accepted definition of leadership does not exist and might never be found. Fred Fiedler (1971), for example, noted: "There are almost as many definitions of leadership as there are leadership theories-and there are almost as many theories of leadership as there are psychologists working in the field" (p. 1). Even in this absence of universal agreement, a broad definition of leadership is required before introducing the construct as a domain of scholarly inquiry.

Most leadership scholars would likely agree, at least in principle, that leadership can be defined in terms of (a) an influencing process-and its resultant outcomes-that occurs between a leader and followers and (b) how this influencing process is explained by the leader's dispositional characteristics and behaviors, follower perceptions and attributions of the leader, and the context in which the influencing process occurs. We recognize that this is a multifaceted definition that is heavily "leader centric" in describing mainly one-way effects associated with the personal characteristics of a leader; however, it also includes aspects of the interaction between leader and follower (in terms of perceptions and attributions) as well as a definition of leadership as an effect with regard to the resulting outcomes (e.g., goal achievement). We also acknowledge that leadership is rooted in a context, which may affect the type of leadership that emerges and whether it will be effective (Liden \& Antonakis, 2009). Our broad definition of leadership thus incorporates the most commonly used definitional features: the leader as person (dispositional characteristics), leader behavior, the effects of a leader, the interaction process between a leader and follower(s), and the importance of context (Bass, 2008).

In setting forth any definition of leadership, it is also important that we differentiate it conceptually from power and management, respectively, because these concepts are often confused with leadership. Power refers to the means leaders have to potentially influence others. Examples include referent power (i.e., followers' identification with the leader), expertise, the ability to reward or punish performance, and the formal power that is accorded legitimately based on one's role (Etzioni, 1964; French \& Raven, 1968). Thus, the ability to lead others requires that one has power.

Regarding its distinction from management, leadership as seen from the "New" perspective (Bryman, 1992) is purpose-driven action that brings about change or transformation based on values, ideals, vision, symbols, and emotional exchanges. Management is objectives driven, resulting in stability grounded in rationality, bureaucratic means, and the fulfillment of contractual obligations (i.e., transactions). Although some view leaders and managers as different sorts of individuals (Zaleznik, 1992), others argue that successful leadership also requires successful management, that leadership and management are complementary, but that leadership goes beyond management, and that leadership is necessary for outcomes that exceed expectations (Bass, 1985, 1998; Bass \& Riggio, 2006). 
At its essence, leadership is functional and necessary for a variety of reasons. On a supervisory level, leadership is required to complement organizational systems (Katz \& Kahn, 1978), establish and recognize group goals and values, recognize and integrate various individual styles and personalities in a group, maximize the use of group members' abilities, and help resolve problems and conflicts in a group (Schutz, 1961, as cited in Bass, 2008). Thus, from a functional perspective, a leader is a "completer" who does or gets done whatever is not being adequately handled by a group (McGrath, 1962). At the strategic level, leadership is necessary to ensure the coordinated functioning of the organization as it interacts with a dynamic external environment (Katz \& Kahn, 1978). That is, the organization must adapt to its context; for this to occur, its leaders must monitor the external and internal environments, formulate a strategy based on the strengths and weakness of the organizations and the opportunities presented by the environment, and monitor outcomes so that its strategic goals are met (Antonakis, House, Rowold, \& Borgmann, 2010). Thus, leadership is required to direct and guide organizational and human resources toward the strategic objectives of the organization and ensure that organizational functions are aligned with the external environment (see Zaccaro, 2001).

\section{The Study of Leadership}

In this section, we discuss how the study of leadership has evolved. Our description is cursory because many of the details relating to the different theoretical perspectives of leadership are discussed in various chapters that follow. Our intention is to provide readers with a general understanding of how leadership theory evolved into the major paradigms presented in this book. We then discuss leadership in special domains and emerging issues relating leadership to culture, gender, ethics, and identity, among others. Finally, we discuss how leadership findings are being integrated into cohesive frameworks (i.e., hybrid approaches).

\section{A Brief History of Leadership Research}

We have divided leadership research into nine major schools (see Figure 1.1) and classified the schools on two dimensions: temporal (i.e., the time period in which the school emerged) and productivity (i.e., the indicative degree to which the school attracted research interest in a specific period of time). The derivation of the schools and the research productivity of the schools are based on our professional judgment; however, we have also been guided by a recent review of the literature that has appeared in the last decade in The Leadership Quarterly (Gardner, Lowe, Moss, Mahoney, \& Cogliser, 2010). We have also relied on several historical reviews (e.g., Bass, 2008; Day, in 
Figure 1.1 A Brief History and Look Into the Future of Leadership Research

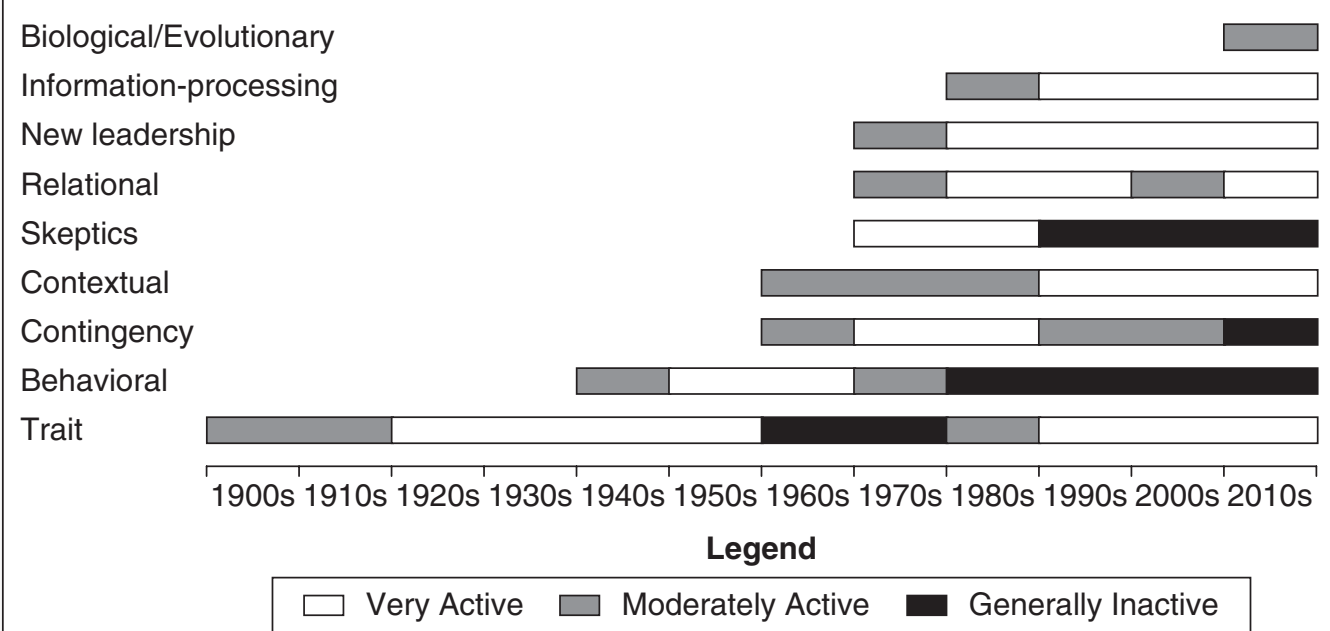

press; House \& Aditya, 1997; Lowe \& Gardner, 2000; Van Seters \& Field, 1990), to which readers can refer for more complete accounts of the history and development of leadership research.

\section{Trait School of Leadership}

The scientific study of leadership began at the turn of the 20th century with the "great man [sic]" or trait-based perspective, which saw the shaping of history through the lens of exceptional individuals. This school of thought suggested that certain dispositional characteristics (i.e., stable personality attributes or traits) differentiated leaders from nonleaders. Thus, leadership researchers focused on identifying robust individual differences in personality traits that were thought to be associated with effective leadership. In two influential reviews (Mann, 1959; Stogdill, 1948), traits such as intelligence and dominance were identified as being associated with leadership. However, trait research, for most intents and purposes, was shut down following the rather pessimistic interpretations of these findings by many leadership scholars (see Day \& Zaccaro, 2007, for a more comprehensive discussion of the history of leadership trait theory).

This was the first major crisis reorientation of leadership research, and it took almost 30 years for this line of research to reemerge. The impetus for the re-emergence of leadership trait theory came from a reanalysis of Mann's data using a relatively new and innovative analytic procedure at the timemeta-analysis (Lord, De Vader, \& Alliger, 1986). This analytic procedure proposed new ways of aggregating effects across studies to more accurately 
estimate effect sizes (Hunter \& Schmidt, 1990). The meta-analytic results offered by Lord et al. suggested that the trait of intelligence was strongly correlated $(r=.50)$ with perceptions of leadership (i.e., emergence rather than effectiveness) and that this effect was robust across studies included in Mann's data as well as studies published subsequent to Mann. More recent meta-analyses confirmed that objectively measured intelligence correlates $(r=.33)$ with leadership effectiveness as well (Judge, Colbert, \& Ilies, 2004). Studies by Kenny and Zaccaro (1983) and Zaccaro, Foti, and Kenny (1991) were also instrumental in demonstrating stable leader characteristics, such as traits related to leader emergence. David McClelland (1985), in the meantime, led another independent line of inquiry linking leader implicit motives (i.e., subconscious drives or wishes) to leader effectiveness (see also House, Spangler, \& Woycke, 1991).

There have been a few high-profile reviews of the trait perspective on leadership and particularly the moderately strong relationship of the big-five personality factors with leader emergence and effectiveness (e.g., Judge, Bono, Ilies, \& Gerhardt, 2002; Zaccaro, 2007); however, there has been a decline in the proportion of articles published in The Leadership Quarterly (LQ) - a prominent specialty journal devoted to leadership theory and research (Gardner et al., 2010). Research efforts in this area, however, shall probably continue as advances are made in psychometric testing and interest in other individual-differences areas (e.g., gender, diversity) increases.

\section{Behavioral School of Leadership}

Given the early pessimistic reviews of the trait literature, leadership researchers began, in the 1950s, focusing on the behavioral styles of leaders. Similar to the Lewin and Lippitt (1938) exposition of democratic versus autocratic leaders, this line of research focused on the behaviors that leaders enacted and how they treated followers. The influential Ohio State (Stogdill \& Coons, 1957) and University of Michigan (Katz, Maccoby, Gurin, \& Floor, 1951) studies identified two overarching leadership factors generally referred to as consideration (i.e., supportive, personoriented leadership) and initiating structure (i.e., directive, task-oriented leadership). Others extended this research to organization-level effects (e.g., Blake \& Mouton, 1964).

Nonetheless, leadership research found itself again in crisis because of contradictory findings relating behavioral "styles" of leadership to relevant outcomes. That is, there was no consistent evidence of a universally preferred leadership style across tasks or situations. From these inconsistent findings, it was proposed that success of the leader's behavioral style must be contingent on the situation. As a result, leadership theory in the 1960s began to focus on leadership contingencies. Interest in behavioral theories per se is currently very low (Gardner et al., 2010); however, many of the ideas of the behavioral movement have been incorporated into other 
perspectives of leadership (e.g., contingency theories, transformational leadership). In addition, recent meta-analytic results suggest that there is perhaps more consistent support for consideration and initiating structure in predicting leadership outcomes than has been generally acknowledged (Judge, Piccolo, \& Ilies, 2004).

\section{Contingency School of Leadership}

The leadership contingency theory movement is credited in large part to Fiedler (1967, 1971), who stated that leader-member relations, task structure, and the position power of the leader determine the effectiveness of the type of leadership exercised. Another well-known contingency approach was that of House (1971), who focused on the leader's role in clarifying paths to follower goals. Kerr and Jermier (1978) extended this line of research into the "substitutes-for-leadership" theory by focusing on the conditions where leadership is unnecessary as a result of factors such as follower capabilities, clear organizational systems, and routinized procedures. Other lines of research, presenting theories of leader decision-making style and various contingencies, include the work of Vroom and associates (e.g., Vroom \& Jago, 1988; Vroom \& Yetton, 1973).

Whereas there is some ongoing interest in contingency theories (e.g., Fiedler, 1993; House, 1996), the overall influence of the approach appears to have tapered off dramatically. Only about $1 \%$ of the articles published in the last decade in LQ focused on contingency theories (Gardner et al., 2010). A contributing factor to this waning interest may be that parts of this literature have led to the development of broader contextual approaches to leadership, which are discussed under emerging issues below.

\section{Relational School of Leadership}

Soon after the contingency movement became popular, another line of research focusing on relationships between leaders and followers (i.e., the relational school) began generating substantial theoretical attention and became the focus of research. This movement was based on what originally was termed vertical dyad linkage theory (Dansereau, Graen, \& Haga, 1975), which evolved into leader-member exchange (LMX) theory (Graen \& Uhl-Bien, 1995). LMX theory describes the nature of the relations between leaders and their followers. High-quality relations between a leader and his or her followers (i.e., the "in group") are based on trust and mutual respect, whereas low-quality relations between a leader and his or her followers (i.e., the "out group") are based on the fulfillment of contractual obligations. LMX theory predicts that high-quality relations generate more positive leader outcomes than do lower quality relations, which has been supported empirically (Gerstner \& Day, 1997; Ilies, Nahrgang, \& Morgeson, 2007). This line of 
research continues to find new directions, and overall interest in relational approaches to leadership appears to be relatively strong, with approximately six percent $(N=40)$ of articles published in $L Q$ between 2000 and 2009 addressing various relational perspectives, including growing interest in the role of followers (Gardner et al., 2010).

\section{Skeptics-of-Leadership School}

Leadership research faced yet other series of challenges in the 1970s and 1980s. The validity of questionnaire ratings of leadership was criticized as likely biased by the implicit leadership theories of those providing the ratings (e.g., Eden \& Leviathan, 1975; Rush, Thomas, \& Lord, 1977). This position suggests that what leaders do (i.e., leadership) is largely attributed based on performance outcomes and may reflect the implicit leadership theories that individuals carry "in their heads" (Eden \& Leviathan, p. 740). That is, people attribute leadership as a way of explaining observed results, even if those results were due to factors outside of the leader's control.

In a related field of research, scholars argued that leader evaluations were based on the attributions followers make in their quest to understand and assign causes to organizational outcomes (Calder, 1977; Meindl \& Ehrlich, 1987; Meindl, Ehrlich, \& Dukerich, 1985). These researchers suggested that what leaders do might be largely irrelevant and that leader outcomes (i.e., the performance of the leader's group) affect how leaders are rated (see Lord, Binning, Rush, \& Thomas, 1978). Another related line of research questioned whether leadership existed at all or was even needed, thus questioning whether it made any difference to organizational performance (Meindl \& Ehrlich, 1987; Pfeffer, 1977).

Many of the above arguments have been addressed by leadership scholars who might be classified as realists rather than skeptics (e.g., Barrick, Day, Lord, \& Alexander, 1991; Day \& Lord, 1988; House et al., 1991; J. E. Smith, Carson, \& Alexander, 1984). Interest in the skeptics' perspective appears to have waned, although there is increasing interest in followers' roles in leadership processes (Gardner et al., 2010). In addressing many of questions posed by the skeptics' school, the study of leadership has benefited from (a) using more rigorous methodologies, (b) differentiating top-level leadership from supervisory leadership and (c) focusing on followers and how they perceive reality. Furthermore, the study of followership and the resultant informationprocessing perspective of leadership have generated many theoretical advances that have strengthened the leadership field immensely.

\section{Information-Processing School of Leadership}

The major impetus for the information-processing perspective is based on the work of Lord and colleagues (e.g., Lord, Foti, \& De Vader, 1984). The focus of the work has mostly been on understanding how and why a 
leader is legitimized (i.e., accorded influence) through the process of matching his or her personal characteristics (i.e., personality traits) with the prototypical expectations that followers have of a leader.

The information-processing perspective has also been extended to better understand how cognition is related to the enactment of various behaviors (e.g., Balkundi \& Kilduff, 2005; Wofford, Goodwin, \& Whittington, 1998). Also notable are the links that have been made to other areas of leadership, for example, prototypes and their relation to various contextual factors (see Lord, Brown, Harvey, \& Hall, 2001; Lord \& Emrich, 2000; Lord \& Maher, 1991). Information-processing perspectives of leadership have generated much attention, and the interest in leader/follower cognitions among contributors to $L Q$ continues to grow (Gardner et al., 2010). As a result, research in the areas of cognition, information processingand emotions-should continue to provide us with novel understandings of leadership.

\section{The New Leadership (Neo-Charismatic/ Transformational/Visionary) School}

At a time when leadership research was beginning to appear especially dull and lacking in any theoretical advances or insights, the work of Bass and his associates (Bass, 1985, 1998; Bass \& Avolio, 1994; Hater \& Bass, 1988) and others promoting visionary and charismatic leadership theories (e.g., Bennis \& Nanus, 1985; Conger \& Kanungo, 1987), reignited interest in leadership research in general (Bryman, 1992; Hunt, 1999) and in related schools of leadership (e.g., trait school).

Bass (1985) built on the work of Burns (1978), House (1977), and others to argue that previous paradigms of leadership were mainly transactional; that is, they were focused on the mutual satisfaction of transactional (i.e., social exchange) obligations. Bass believed that a different form of leadership was required to account for follower outcomes centered on a sense of purpose and an idealized mission. He referred to this type of leadership as transformational leadership, in which idealized and inspiring leader behaviors induced followers to transcend their interests for that of the greater good; the Bass model has federated much of the research in this area (Antonakis \& House, 2002). Transformational and charismatic leadership, and other models categorized under the heading of "Neo-charismatic" approaches, make up the single most dominant leadership paradigm over the past decade; however, the overall proportion of published $L Q$ articles stemming from this school has dropped from 34\% between 1990 and 1999 to about 13\% from 2000 to 2009 (Gardner et al., 2010). It holds the top spot in terms of published LQ articles. Gardner et al. attributed its proportional drop to the increase of various approaches classified as "New Directions" (e.g., contextual approaches, leadership development, authentic leadership) in the same time period-from $14 \%$ to more than $44 \%$. 


\section{Biological and Evolutionary Perspectives}

We are including a new research stream, which is related somewhat to the trait perspective of leadership in terms of measuring individual differences. This perspective, however, is more of a hard-science approach in terms of measuring directly observable individual differences (e.g., biological variables or processes) and also of considering why certain variables might provide an evolutionary advantage to an organism. This research stream is novel and is currently producing interesting research from looking at the behavioral genetics of leadership emergence (Ilies, Gerhardt, \& Le, 2004) to leadership role occupancy, both in men and women (Arvey, Rotundo, Johnson, Zhang, \& McGue, 2006; Arvey, Zhang, Avolio, \& Krueger, 2007; Ilies et al., 2004). Other interesting avenues include studying the effect of hormones on correlates of leadership, for example dominance (Grant \& France, 2001; Gray \& Campbell, 2009; Sellers, Mehl, \& Josephs, 2007; Zyphur, Narayanan, Koh, \& Koh, 2009), neuroscientific perspectives of leadership (Antonakis, Ashkanasy, \& Dasborough, 2009; Chiao, Mathur, Harada, \& Lipke, 2009; Villarejo \& Camacho, 2009), evolutionary points of view (Antonakis \& Dalgas, 2009; Kramer, Arend, \& Ward, 2010; K. B. Smith, Larimer, Littvay, \& Hibbing, 2007; Van Vugt \& Schaller, 2008), as well as integrative biological perspectives (Caldu \& Dreher, 2007). This perspective might be poised to make major contributions in understanding the sociobiology of leadership. Interest in the area is spreading, as indicated by a forthcoming special issue of The Leadership Quarterly that is titled "Towards a Biology of Leadership."

\section{Emerging Issues}

We currently have a fundamental understanding of leadership, but there are still many areas that are in need of additional research. We briefly discuss some of these areas, which include context, ethics, and diversity issues related to leadership. We also discuss how future leadership research might be consolidated.

Related to the contingency movement is the Contextual School of leadership (e.g., (Hannah, Uhl-Bien, Avolio, \& Cavaretta, 2009; Osborn, Hunt, \& Jauch, 2002; Porter \& McLaughlin, 2006; Shamir \& Howell, 1999). From this perspective, contextual factors are seen to give rise to or inhibit certain leadership behaviors or their dispositional antecedents (Liden \& Antonakis, 2009). These contextual factors can include leader hierarchical level, national culture, leader-follower gender, and organizational characteristics, among other factors (Antonakis, Avolio, \& Sivasubramaniam, 2003). Understanding the contextual factors in which leadership is embedded is necessary for advancing a more general understanding of leadership. Simply put, leadership does not occur in a vacuum (House \& Aditya, 1997), and context and leadership appear to be intertwined. 
Ethics is another important emerging topic in leadership research (Brown $\&$ Treviño, 2006). It is surprising that ethics and ethical leadership has not been a mainstay of leadership researchers. Indeed, Bass (1985)-one of the most prominent figures in the field-did not make the distinction between authentic (i.e., ethical) and inauthentic (i.e., unethical) transformational leaders until more than a decade after he published his theory (see Bass, 1998; Bass \& Steidlemeier, 1999). The ethics of leadership and a leader's level of moral development are increasingly becoming essential elements of leadership research and theory (Turner, Barling, Epitropaki, Butcher, \& Milner, 2002). Future leadership models should consider the ethics of leader means and ends, as well as ways in which leader moral orientation can be developed and otherwise improved (Day, Harrison, \& Halpin, 2009).

Issues regarding diversity and leadership have been highlighted as receiving relatively scarce attention in the literature (Eagly \& Chin, 2010). In particular, the diversity of leaders and followers in terms of culture, gender, race and ethnicity, or sexual orientation has been infrequently addressed. Advances in theory and research are more notable in the areas of culturethanks in large part to the Project GLOBE studies (House, Hanges, Javidan, Dorfman, \& Gupta, 2004)—and gender through the work of Alice Eagly and colleagues (see Eagly \& Carli, 2007, for a summary and overview of major findings). The literature with regard to leadership and race, ethnicity, and sexual orientation (in particular) is presently relatively unformed; however, there are some early attempts to identify and describe the challenges associated with leading across racial differences in organizations (e.g., Livers \& Caver, 2003). Clearly, there is a need for additional theory building and empirical research directed at the numerous facets involved with diversity and leadership.

Given how much is currently known about the nature of leadership, we believe that researchers are in a position to integrate overlapping and complementary conceptualizations of leadership. Van Seters and Field (1990) argued that the new era of leadership research will be one of converging evidence and integration. In a similar vein-and almost 20 years laterAvolio (2007) urged the promotion of more integrative strategies for leadership theory building. It appears that our accumulated knowledge is such that we can begin to construct hybrid theories of leadership, or even hybridintegrative perspectives (i.e., integrating diverse perspectives), including not only psychological and contextual variables but biological ones as well (Antonakis, 2011). An example of an integrative perspective includes the work of House and Shamir (1993), who integrated various "new" leadership theories. Zaccaro's (2001) hybrid framework of executive leadership links cognitive, behavioral, strategic, and visionary leadership theory perspectives. Zaccaro's work is also a good example of a hybrid-integrative perspective, given that he also integrated overlapping perspectives of leadership. Another recent example of a hybrid-integrative framework is the integrative approach to leader development proposed by Day et al. (2009) that seeks to connect 
the relatively disparate fields of expertise and expert performance, identity and self-regulation, and adult development.

There are many other ways in which hybrid approaches could be developed. For example, LMX theory-included under the "Relational School of Leadership" - has been criticized for not specifying behavioral antecedents of high- or low-quality relations (see House \& Aditya, 1997). LMX could potentially be integrated with the transformational-transactional leadership theory, in that the style of leadership employed is thought to be related to the type of leader-follower relations and exchanges (see Deluga, 1990; Gerstner \& Day, 1997; Howell \& Hall-Merenda, 1999).

It is only through efforts to consolidate findings that leadership research will go to the next level where we may finally be able to construct and test more general theories of leadership. Previous research has laid the foundations for such theories. Now leadership researchers need to begin to conceptualize ways in which many of the diverse findings can be united and otherwise synthesized and integrated, examples of which are evident throughout the chapters of this book.

\section{Organization and Summary of the Book}

We have introduced readers to the major paradigms and current issues relating to leadership. In the remainder of this chapter, we provide a summary of the chapters that compose the second edition of the Nature of Leadership.

\section{Part II: Leadership: Science, Nature, and Nurture}

Chapter 2: Lord and Dinh (Aggregation Processes and Levels of Analysis as Organizing Structures for Leadership Theory) propose that theoretical integration in the leadership field requires a better system for addressing levels of analyses issues. They argue that it is necessary to distinguish among global, shared, and configural properties because each reflects a different form of aggregation from lower-level units. Lord and Dinh then apply this distinction to consider leadership at the level of events, individuals, groups, and organizations. Working with this system provides for new insights regarding the shared functions and antecedents of various leadership theories. It represents a major integrative advancement in leadership theory in exploring aggregation processes and levels of analysis as fundamental organizing structures for leadership theory.

Chapter 3: Zyphur, Barsky, and Zhang (Advances in Leadership Research Methods) describe five advanced quantitative techniques that they hope will prove useful to leadership researchers. The techniques are (a) latent polynomial regression, which introduces a new and improved congruence 
model; (b) multilevel member weighted modeling (MWM) that shows how observed variables may be used to weight the contributions of individual group members when estimating group averages in multilevel modeling; (c) intercept-as-mean latent growth modeling (IGM) that shows how researchers can set latent intercept factors to estimate each individual's average score across observations over time; (d) multilevel structural equation modeling that addresses noted limitations in regular structural equation modeling and multilevel models, respectively; and (e) latent class cluster analysis as a method for examining profiles among multiple observed variables such as leadership styles or personality traits. Zyphur and colleagues demonstrate how each model provides a novel mindset for asking new questions and studying traditional leadership questions in novel ways.

Chapter 4: Day (The Nature of Leadership Development) examines a number of fundamental questions with regard to the nature of leadership development and evaluates the available evidence regarding each question. The question of whether leaders are born or made has been addressed in a series of studies comparing identical and fraternal twins, suggesting that as much as $70 \%$ of leadership capability could be shaped by nurture (i.e., experience). Recent longitudinal evidence informing the question of whether leaders can and do develop over time is summarized, followed by an analysis of what is it that develops as a function of leadership development (i.e., what are the competencies or expertise facets that develop?). The chapter then reviews the available practices on how to best promote leadership development. It concludes with a look toward how to improve the science and practice of leadership development in terms of better supporting an evidence-based approach to the field.

Chapter 5: Van Vugt (The Nature in Leadership: Evolutionary, Biological, and Social Neuroscience Perspectives) proposes Evolutionary Leadership Theory (ELT) as a new approach to the study of leadership, connecting the diverse lines of research in the social, biological, economic, and cognitive sciences. It provides an overarching framework that is consistent with Darwin's evolutionary theory, which he refers to as "Darwin's Toolbox." Van Vugt argues that it is important to study the evolutionary origins and functions of leadership so as to better comprehend the veritable "nature" in leadership. In particular, ELT connects many older findings, helps generate novel hypotheses, and tests them with a diversity of methodologies from behavioral genetics to neuroscience and from experimentation to game theory.

\section{Part III: The Major Schools of Leadership}

Chapter 6: Judge and Long (Individual Differences in Leadership) urge students and scholars of the leadership field to keep three things in perspective. First, individual differences matter, and they provide a useful starting point 
for theory building. Second, leaders demonstrate different states and styles based on their dispositions as well as through the individual differences of followers. Third, leaders do not operate in a vacuum, and context can play a significant role in leadership outcomes. From these assumptions, Judge and Long propose and evaluate an evidence-based model of individual differences in leadership that links leader traits with leader states and styles as mediators predicting leader emergence and effectiveness. Moderators in the forms of leader and follower individual differences and contextual factors are also addressed. The authors also explore paradoxical effects associated with "dark side" facets of leader individual differences on emergence and effectiveness outcomes.

Chapter 7: Ayman and Adams (Contingencies, Context, Situation, and Leadership) review situational and contingency theories of leadership suggesting that relations between leader characteristics (e.g., traits, behaviors) and leader outcomes depend on the situation in which the influencing processes occur. They argue that the success of leadership is a function of contingencies, some contextual and some intrapersonal, which moderate the relations of leader characteristics to leader outcomes. Ayman and Adams also clarify a common misunderstanding that a leader's style is fixed. They differentiated style as either trait based, which is fairly consistent, or behavior based, which is malleable. They argue that leaders are capable of monitoring the environment and adjusting their responses to fit a particular context. A combination of leadership skills and competencies such as sensitivity, responsiveness, and flexibility may help leaders reach "mettle"defined as the optimal match between leader characteristics and the situational context.

Chapter 8: Antonakis (Transformational and Charismatic Leadership) reviews the available evidence on "Neo-charismatic" theories of leadership, especially its transformational and charismatic forms. In his comprehensive historical analysis, he explains how these approaches came to fore and currently dominate the leadership landscape. He concludes that even though research in the field is mature, there is still much that needs to be done to improve these models. In particular, Antonakis points to outstanding needs for (a) more longitudinal and multilevel research, (b) the development of more inclusive and less biased questionnaire measures including objective measures, and (c) a fuller understanding of process models that also consider contextual effects and individual-difference antecedents. These are important issues to understand because as history attests, future leaders will continue to emerge who wield charismatic power.

Chapter 9: Uhl-Bien, Maslyn, and Ospina (The Nature of Relational Leadership: A Multitheoretical Lens on Leadership Relationships and Processes) adopt a multi-paradigmatic and multiple-theory lens to relational 
leadership. They draw from findings regarding relationships across a variety of literature and perspectives to provide a review of relational leadership from the standpoint of leader-follower relationships (e.g., dyadic relationship quality) and leadership "relationality" (e.g., relational processes and collective practices). Uhl-Bien and colleagues outline a broad, cross-disciplinary and multiple-method research program that focuses not just on LMX measures but on the wider examination of leadership relationships (dyadic and collective) and relational processes and practices. This agenda calls for including consideration of constructionist approaches that can help advance study of the nature of relationships, their development, and relational organizing (e.g., shared patterns of meaning making, conjoint agency, and coordinated behavior through which leadership is enacted). They conclude by challenging leadership scholars to take seriously the need to consider relationality in leadership research.

Chapter 10: Brown (In the Minds of Followers: Follower-Centric Approaches to Leadership) considers key assumptions about followers and the role that followers have played in much of the previous leadership literature. In furthering a follower-centric perspective on leadership, he argues that if we are to understand why followers behave as they do, a necessary first step is in understanding their thought processes, mainly in the form of information-processing activities. Two core questions are examined in the chapter. First, why is it that we understand the world through leaders? Second, what is the nature of our mental leader category and how does it influence followers' perceptions of leaders? Brown addresses these questions through a review of the foundational theory and research that informs our understanding of the information processing that is behind our leadership perceptions.

Chapter 11: Wassenaar and Pearce (The Nature of Shared Leadership) offer a foundational view of shared leadership defined as a dynamic, interactive influence process among individuals in groups where the objective is to lead one another to achieve group and organizational goals. The focus of shared leadership is not on the leader as with dominant leader-centric approaches but on how individuals in a team or organization can be $a$ leader along with other members. The authors evaluate recent evidence on the antecedents and outcomes of shared leadership, review various approaches to the measurement of shared leadership, and explore future directions in theory and research on shared leadership.

\section{Part IV: Leadership and Special Domains}

Chapter 12: Den Hartog and Dickson (Leadership and Culture) take a contextual approach in reviewing research on the relation between leadership 
and national (i.e., societal) culture. They draw on literature from cultural anthropology and cross-cultural psychology to show that national culture equips individuals with common ways of perceiving and acting, which systemically affect what followers expect from leaders and how leaders enact their behaviors. They show that certain leader traits and behaviors may be context specific and that others may be universal, but differentially enacted according to national culture and context. Ultimately, Den Hartog and Dickson show that we should not take for granted that leadership models and theories developed in one culture will apply similarly in another. They describe culture at the societal and organizational level and show how culture can affect implicit leadership theories and behavior. Finally, they highlight the developing world in recognizing a new set of challenges to leadership scholars, given that most of our literature is steeped in cultural assumptions from the so-called developed countries of the world.

Chapter 13: Carli and Eagly (Leadership and Gender) focus on the contextual perspective of gender-based expectations of leaders and how they constrain the type of leadership that is enacted. They discuss the validity of arguments related to male-female difference from various perspectives, including societal, evolutionary, and prejudicial. Literature is reviewed demonstrating that women may not have the same opportunities to lead and that women are more constrained in the behaviors they can display than are men. They explore five explanations offered for women's scarce occupancy of high-level leadership positions and conclude that the evidence suggests the only plausible explanations reside in prejudice and discrimination against women leaders. Even though women leaders are disadvantaged by stereotypes and restricted role expectations, they are as effective as are men leaders, and women actually display certain prototypically effective leader styles more often than do men. Carli and Eagly ultimately conclude that economic necessity and fundamental issues of fairness require facilitating faster entry of women into the leadership ranks in the future.

Chapter 14: van Knippenberg (Leadership and Identity) provides an overview of the identity approach to leadership. Fundamental to this approach is the notion that identity shapes perceptions, attitudes, and behavior. In short, identity can be a powerful motivating force and a focus on leader and follower identity is instrumental in understanding leadership effectiveness. The research evidence is consistent that identity matters when it comes to understanding leadership processes and outcomes. van Knippenberg urges further development of the identity perspective on leadership as a possible means of fostering integration in the field and building more broad-ranging accounts of leadership. 
Chapter 15: Ciulla (Ethics and Effectiveness: The Nature of Good Leadership) focuses on another emerging issue: ethics and leader effectiveness. She writes from the unique perspective of a philosopher, making clear the limitations of traditional leadership theorists' attempts to weave ethics into their theories by simply exhorting that ethical leadership is important. Although inroads have been made by some leadership scholars, Ciulla shows how philosophy can be used to highlight ethical dilemmas of leaders, how to judge the ethics of leader outcomes, and the implications for leader-follower relations. Ciulla sees leader ethics and leader outcomes as inextricably intertwined. In addition, she presents a persuasive argument that leaders cannot be considered effective unless they are ethical.

\section{Part V: Conclusion}

Chapter 16: Bennis (The Crucibles of Authentic Leadership) uses an engaging writing style in taking the reader along on an Odyssey of leadership. He provides practical examples, subtly integrating and applying many of the book's themes, and brings to light the nature of authentic leadership. He touches on numerous issues and how they relate to leader emergence and effectiveness, focusing on leader traits, experiential learning, coalition building, contexts and contingencies, national culture, and so forth. He concludes with how leadership research should be taken to the next level by studying it using multidisciplinary paradigms. He relates the issues discussed to historical events and to the interplay of factors that "make" leaders. These are the "crucibles" of leadership, conditions in which leaders face great tests and crises, from which they emerge, molded with a vision and values to inspire others to do what is morally correct.

We hope to introduce you to what we believe is a fascinating body of leadership literature. The complexity and mystique surrounding leadership evolve into understanding as you read the chapters that follow. In the last century, the often-misunderstood phenomenon of leadership has been tossed and battered while social scientists tried to make sense of a force they knew was important, but which seemed beyond the reach of scientific inquiry. Remarking about the difficulties leadership researchers have faced, Bennis (1959, p. 260) noted: "Always, it seems, the concept of leadership eludes us or turns up in another form to taunt us again with its slipperiness and complexity."

The concept is still complex-perhaps more so than at any other point in history-but it is better understood and less elusive. We still have much to learn about leadership, but we are guided by a spirit of optimism emanating from the findings of those researchers before us who went through their own "crucibles." Bloodied in a sense but unbowed, they continued to study leadership and to inspire succeeding generations of scientists to continue their 
exploration. All the while, leaders influenced followers and will continue to do so, regardless of the fads, follies, and folderol that have distracted leadership researchers in the past.

\section{References}

Antonakis, J. (2011). Predictors of leadership: The usual suspects and the suspect traits. In A. Bryman, D. Collinson, K. Grint, B. Jackson \& M. Uhl-Bien (Eds.), Sage handbook of leadership. Thousand Oaks, CA: Sage, 269-285.

Antonakis, J., Ashkanasy, N. M., \& Dasborough, M. T. (2009). Does leadership need emotional intelligence? The Leadership Quarterly, 20, 247-261.

Antonakis, J., Avolio, B. J., \& Sivasubramaniam, N. (2003). Context and leadership: An examination of the nine-factor full-range leadership theory using the Multifactor Leadership Questionnaire. The Leadership Quarterly, 14, 261-295.

Antonakis, J., \& Dalgas, O. (2009). Predicting elections: Child's play! Science, 323(5918), 1183.

Antonakis, J., \& House, R. J. (2002). An analysis of the full-range leadership theory: The way forward. In B. J. Avolio \& F. J. Yammarino (Eds.), Transformational and charismatic leadership: The road ahead (pp. 3-34). Amsterdam, Netherlands: JAI.

Antonakis, J., House, R. J., Rowold, J., \& Borgmann, L. (2010). A fuller full-range leadership theory: Instrumental, transformational, and transactional leadership. Unpublished manuscript.

Arvey, R. D., Rotundo, M., Johnson, W., Zhang, Z., \& McGue, M. (2006). The determinants of leadership role occupancy: Genetic and personality factors. The Leadership Quarterly, 17, 1-20.

Arvey, R. D., Zhang, Z., Avolio, B. J., \& Krueger, R. F. (2007). Developmental and genetic determinants of leadership role occupancy among women. Journal of Applied Psychology, 92, 693-706.

Avolio, B. J. (2007). Promoting more integrative strategies for leadership theorybuilding. American Psychologist, 62, 25-33.

Balkundi, P., \& Kilduff, M. (2005). The ties that lead: A social network approach to leadership. The Leadership Quarterly, 16, 941-961.

Barrick, M. R., Day, D. V., Lord, R. G., \& Alexander, R. A. (1991). Assessing the utility of executive leadership. The Leadership Quarterly, 2, 9-22.

Bass, B. M. (1985). Leadership and performance beyond expectations. New York: Free Press.

Bass, B. M. (1998). Transformational leadership: Industrial, military, and educational impact. Mahwah, NJ: Lawrence Erlbaum.

Bass, B. M. (2008). The Bass handbook of leadership: Theory, research, and managerial applications (4th ed.). New York: Free Press.

Bass, B. M., \& Avolio, B. J. (1994). Transformational leadership: Improving organizational effectiveness. Thousand Oaks, CA: Sage.

Bass, B. M., \& Riggio, R. E. (2006). Transformational leadership (2nd ed.). Mahwah, NJ: Lawrence Erlbaum.

Bass, B. M., \& Steidlemeier, P. (1999). Ethics, character, and authentic transformational leadership behavior. The Leadership Quarterly, 10, 181-217. 
Bennis, W. (1959). Leadership theory and administrative behavior. Administrative Science Quarterly, 4, 259-301.

Bennis, W. (2007). The challenges of leadership in the modern world. American Psychologist, 62, 2-5.

Bennis, W., \& Nanus, B. (1985). Leaders: The strategies for taking charge. New York: HarperCollins.

Blake, R. R., \& Mouton, J. S. (1964). The managerial grid. Houston, TX: Gulf.

Brown, M. E., \& Treviño, L. K. (2006). Ethical leadership: A review and future directions. The Leadership Quarterly, 17, 595-616.

Bryman, A. (1992). Charisma and leadership in organizations. Newbury Park, CA: Sage.

Burns, J. M. (1978). Leadership. New York: Harper \& Row.

Calder, B. J. (1977). An attribution theory of leadership. In B. M. Staw \& G. R. Salancik (Eds.), New directions in organizational behavior (pp. 179-204). Chicago: St. Clair.

Caldu, X., \& Dreher, J. C. (2007). Hormonal and genetic influences on processing reward and social information. In C. Senior \& M. J. R. Butler (Eds.), Social cognitive neuroscience of organizations (Vol. 1118, pp. 43-73). Oxford, UK: Basil Blackwell.

Chiao, J. Y., Mathur, V. A., Harada, T., \& Lipke, T. (2009). Neural basis of preference for human social hierarchy versus egalitarianism. In S. Atran, A. Navarro, K. Ochsner, A. Tobena \& O. Vilarroya (Eds.), Values, empathy, and fairness across social barriers (Vol. 1167, pp. 174-181). Oxford, UK: Basil Blackwell.

Conger, J. A., \& Kanungo, R. N. (1987). Toward a behavioral theory of charismatic leadership in organizations. Academy of Management Review, 12, 637-647.

Dansereau, F., Jr., Graen, G., \& Haga, W. J. (1975). A vertical dyad linkage approach to leadership within formal organizations: A longitudinal investigation of the role making process. Organizational Behavior and Human Performance, 13, 46-78.

Day, D. V. (in press). Leadership. In S. W. J. Kozlowski (Ed.), The Oxford handbook of organizational psychology. New York: Oxford University Press.

Day, D. V., Harrison, M. M., \& Halpin, S. M. (2009). An integrative approach to leader development: Connecting adult development, identity, and expertise. New York: Routledge.

Day, D. V., \& Lord, R. G. (1988). Executive leadership and organizational performance: Suggestions for a new theory and methodology. Journal of Management, 14, 453-464.

Day, D. V., \& Zaccaro, S. J. (2007). Leadership: A critical historical analysis of the influence of leader traits. In L. L. Koppes (Ed.), Historical perspectives in industrial and organizational psychology (pp. 383-405). Mahwah, NJ: Lawrence Erlbaum.

Deluga, R. J. (1990). The relationship of leader-member exchanges with laissez-faire, transactional, and transformational leadership in naval environments. In K. E. Clark, M. B. Clark, \& D. P. Campbell (Eds.), Impact of leadership (pp. 237-247). Greensboro, NC: Center for Creative Leadership.

Eagly, A. H., \& Carli, L. L. (2007). Through the labyrinth: The truth about how women become leaders. Boston, MA: Harvard Business School Press.

Eagly, A. H., \& Chin, J. L. (2010). Diversity and leadership in a changing world. American Psychologist, 65, 216-224. 
Eden, D., \& Leviathan, U. (1975). Implicit leadership theory as a determinant of the factor structure underlying supervisory behavior scales. Journal of Applied Psychology, 60, 736-741.

Etzioni, A. (1964). Modern organizations. Englewood Cliffs, NJ: Prentice Hall.

Fiedler, F. E. (1967). A theory of leadership effectiveness. New York: McGraw-Hill.

Fiedler, F. E. (1971). Leadership. Morristown, NJ: General Learning.

Fiedler, F. E. (1993). The leadership situation and the black box in contingency theories. In M. M. Chemers \& R. Ayman (Eds.), Leadership theory and research: Perspectives and directions (pp. 1-28). San Diego, CA: Academic Press.

French, J. R. P., \& Raven, B. H. (1968). The bases of social power. In D. Cartwright \& A. Zander (Eds.), Group dynamics: Research and theory (3rd ed., pp. 259-269). New York: Harper \& Row.

Gardner, W. L., Lowe, K. B., Moss, T. W., Mahoney, K. T., \& Cogliser, C. C. (2010). Scholarly leadership of the study of leadership: A review of The Leadership Quarterly's second decade, 2000-2009. The Leadership Quarterly, 21, 922-958.

Gerstner, C. R., \& Day, D. V. (1997). Meta-analytic review of leader-member exchange theory: Correlates and construct issues. Journal of Applied Psychology, $82,827-844$.

Graen, G. B., \& Uhl-Bien, M. (1995). Relationship-based approach to leadership: Development of leader-member exchange (LMX) theory of leadership over 25 years: Applying a multi-level multi-domain perspective. The Leadership Quarterly, 6, 219-247.

Grant, V. J., \& France, J. T. (2001). Dominance and testosterone in women. Biological Psychology, 58, 41-47.

Gray, P. B., \& Campbell, B., C. (2009). Human male testosterone, pair-bonding, and fatherhood. In P. T. Ellison \& P. B. Gray (Eds.), Endocrinology of social relationships (pp. 270-293). Cambridge, MA: Harvard University Press.

Greene, C. N. (1977). Disenchantment with leadership research: Some causes, recommendations, and alternative directions. In J. G. Hunt \& L. L. Larson (Eds.), Leadership: The cutting edge (pp. 57-67). Carbondale, IL: Southern Illinois University Press.

Hackman, J. R., \& Wageman, R. (2007). Asking the right questions about leadership. American Psychologist, 62, 43-47.

Hannah, S. T., Uhl-Bien, M., Avolio, B. J., \& Cavaretta, F. L. (2009). A framework for examining leadership in extreme contexts. The Leadership Quarterly, 20, 897-919.

Hater, J. J., \& Bass, B. M. (1988). Superiors' evaluations and subordinates' perceptions of transformational and transactional leadership. Journal of Applied Psychology, 73, 695-702.

House, R. J. (1971). A path-goal theory of leader effectiveness. Administrative Science Quarterly, 16, 321-338.

House, R. J. (1977). A 1976 theory of charismatic leadership. In J. G. Hunt \& L. L. Larson (Eds.), Leadership: The cutting edge (pp. 189-207). Carbondale, IL: Southern Illinois University Press.

House, R. J. (1996). Path-goal theory of leadership: Lessons, legacy, and a reformulated theory. The Leadership Quarterly, 7, 323-352.

House, R. J., \& Aditya, R. N. (1997). The social scientific study of leadership: Quo vadis? Journal of Management, 23, 409-473. 
House, R. J., Hanges, P. J., Javidan, M., Dorfman, P. W., \& Gupta, V. (Eds.). (2004). Culture, leadership, and organizations: The GLOBE Study of 62 societies. Thousand Oaks, CA: Sage.

House, R. J., \& Shamir, B. (1993). Towards an integration of transformational, charismatic, and visionary theories of leadership. In M. M. Chemers \& R. Ayman (Eds.), Leadership: Perspectives and research directions (pp. 81-107). New York: Academic Press.

House, R. J., Spangler, W. D., \& Woycke, J. (1991). Personality and charisma in the U.S. presidency: A psychological theory of leader effectiveness. Administrative Science Quarterly, 36, 364-396.

Howell, J. M., \& Hall-Merenda, K. E. (1999). The ties that bind: The impact of leader-member exchange, transformational and transactional leadership, and distance on predicting follower performance. Journal of Applied Psychology, 84, 680-694.

Hunt, J. G. (1999). Transformational/charismatic leadership's transformation of the field: An historical essay. The Leadership Quarterly, 10, 129-144.

Hunter, J. E., \& Schmidt, F. L. (1990). Methods of meta-analysis: Correcting error and bias in research findings. Newbury Park, CA: Sage.

Ilies, R., Gerhardt, M. W., \& Le, H. (2004). Individual differences in leadership emergence: Integrating meta-analytic findings and behavioral genetics estimates. International Journal of Selection and Assessment, 12, 207-219.

Ilies, R., Nahrgang, J. D., \& Morgeson, F. P. (2007). Leader-member exchange and citizenship behaviors: A meta-analysis. Journal of Applied Psychology, 92, 269-277.

Judge, T. A., Bono, J. E., Ilies, R., \& Gerhardt, M. W. (2002). Personality and leadership: A qualitative and quantitative review. Journal of Applied Psychology, 87, 765-780.

Judge, T. A., Colbert, A. E., \& Ilies, R. (2004). Intelligence and leadership: A quantitative review and test of theoretical propositions. Journal of Applied Psychology, $89,542-552$.

Judge, T. A., Piccolo, R. F., \& Ilies, R. (2004). The forgotten ones? The validity of consideration and initiating structure in leadership research. Journal of Applied Psychology, 89, 36-51.

Katz, D., \& Kahn, R. L. (1978). The social psychology of organizations (2nd ed.). New York: John Wiley.

Katz, D., Maccoby, N., Gurin, G., \& Floor, L. G. (1951). Productivity, supervision and morale among railroad workers. Ann Arbor, MI: Institute for Social Research, University of Michigan.

Kenny, D. A., \& Zaccaro, S. J. (1983). An estimate of variance due to traits in leadership. Journal of Applied Psychology, 68, 678-685.

Kerr, S., \& Jermier, J. (1978). Substitutes for leadership: Their meaning and measurement. Organizational Behavior and Human Performance, 22, 375-403.

Kramer, R. S. S., Arend, I., \& Ward, R. (2010). Perceived health from biological motion predicts voting behaviour. Quarterly Journal of Experimental Psychology, 63, 625-632.

Lewin, K., \& Lippitt, R. (1938). An experimental approach to the study of autocracy and democracy: A preliminary note. Sociometry, 1, 292-300.

Liden, R. C., \& Antonakis, J. (2009). Considering context in psychological leadership research. Human Relations, 62, 1587-1605. 
Livers, A. B., \& Caver, K. A. (2003). Leading in black and white: Working across the racial divide in corporate America. San Francisco: Jossey-Bass.

Lord, R. G., Binning, J. F., Rush, M. C., \& Thomas, J. C. (1978). The effect of performance cues and leader behavior on questionnaire ratings of leadership behavior. Organizational Behavior and Human Performance, 21, 27-39.

Lord, R. G., Brown, D. J., Harvey, J. L., \& Hall, R. J. (2001). Contextual constraints on protoype generation and their multi-level consequences for leadership perceptions. The Leadership Quarterly, 12, 311-338.

Lord, R. G., De Vader, C. L., \& Alliger, G. M. (1986). A meta-analysis of the relation between personality traits and leadership perceptions: An application of validity generalization procedures. Journal of Applied Psychology, 71, 402-409.

Lord, R. G., \& Emrich, C. G. (2000). Thinking outside the box by looking inside the box: Extending the cognitive revolution in leadership research. The Leadership Quarterly, 11, 551-579.

Lord, R. G., Foti, R. J., \& De Vader, C. L. (1984). A test of leadership categorization theory: Internal structure, information processing, and leadership perceptions. Organizational Behavior and Human Performance, 34, 343-378.

Lord, R. G., \& Maher, K. J. (1991). Leadership and information processing: Linking perceptions and performance. Boston, MA: Unwin Hyman.

Lowe, K. B., \& Gardner, W. L. (2000). Ten years of The Leadership Quarterly: Contributions and challenges for the future. The Leadership Quarterly, 11, 459-514.

Mann, R. D. (1959). A review of the relationships between personality and performance in small groups. Psychological Bulletin, 56, 241-270.

McClelland, D. C. (1985). How motives, skills, and values determine what people do. American Psychologist, 40, 812-825.

McGrath, J. E. (1962). Leadership behavior: Some requirements for leadership training. Washington, DC: U.S. Civil Service Commission, Office of Career Development.

Meindl, J. R., \& Ehrlich, S. B. (1987). The romance of leadership and the evaluation of organizational performance. Academy of Management Journal, 30, 90-109.

Meindl, J. R., Ehrlich, S. B., \& Dukerich, J. M. (1985). The romance of leadership. Administrative Science Quarterly, 30, 78-102.

Miner, J. B. (1975). The uncertain future of the leadership concept: An overview. In J. G. Hunt \& L. L. Larson (Eds.), Leadership frontiers (pp. 197-208). Kent, $\mathrm{OH}:$ Kent State University Press.

Osborn, R. N., Hunt, J. G., \& Jauch, L. R. (2002). Toward a contextual theory of leadership. The Leadership Quarterly, 13, 797-837.

Pfeffer, J. (1977). The ambiguity of leadership. Academy of Management Review, 2, 104-112.

Porter, L. W., \& McLaughlin, G. B. (2006). Leadership and organizational context: Like the weather? The Leadership Quarterly, 17, 559-576.

Rush, M. C., Thomas, J. C., \& Lord, R. G. (1977). Implicit leadership theory: A potential threat to the internal validity of leader behavior questionnaires. Organizational Behavior and Human Performance, 20, 756-765.

Schriesheim, C. A., \& Kerr, S. (1977). Theories and measures of leadership: A critical appraisal. In J. G. Hunt \& L. L. Larson (Eds.), Leadership: The cutting edge (pp. 9-45). Carbondale, IL: Southern Illinois University Press. 
Sellers, J. G., Mehl, M. R., \& Josephs, R. A. (2007). Hormones and personality: Testosterone as a marker of individual differences. Journal of Research in Personality, 41, 126-138.

Shamir, B., \& Howell, J. M. (1999). Organizational and contextual influences on the emergence and effectiveness of charismatic leadership. The Leadership Quarterly, 10, 257-283.

Smith, J. E., Carson, K. P., \& Alexander, R. A. (1984). Leadership: It can make a difference. Academy of Management Journal, 27, 765-776.

Smith, K. B., Larimer, C. W., Littvay, L., \& Hibbing, J. R. (2007). Evolutionary theory and political leadership: Why certain people do not trust decision makers. Journal of Politics, 69, 285-299.

Stogdill, R. M. (1948). Personal factors associated with leadership: A survey of the literature. Journal of Psychology, 25, 35-71.

Stogdill, R. M., \& Coons, A. E. (Eds.). (1957). Leader behavior: Its description and measurement. Columbus, OH: Ohio State University, Bureau of Business Research.

Turner, N., Barling, J., Epitropaki, O., Butcher, V., \& Milner, C. (2002). Transformational leadership and moral reasoning, Journal of Applied Psychology, 87, 304-311.

Van Seters, D. A., \& Field, R. H. G. (1990). The evolution of leadership theory. Journal of Organizational Change Management, 3, 29-45.

Van Vugt, M., \& Schaller, M. (2008). Evolutionary approaches to group dynamics: An introduction. Group Dynamics: Theory, Research, and Practice, 12, 1-6.

Villarejo, A., \& Camacho, A. (2009). Neuropoliticis: Neuroscience visits politics. Neurologia, 5(Suppl. 1), 8-11.

Vroom, V. H., \& Jago, A. G. (1988). The new leadership: Managing participation in organizations. Englewood Cliffs, NJ: Prentice Hall.

Vroom, V. H., \& Yetton, P. W. (1973). Leadership and decision making. Pittsburgh, PA: University of Pittsburgh Press.

Wofford, J. C., Goodwin, V. L., \& Whittington, J. L. (1998). A field study of a cognitive approach to understanding transformational and transactional leadership. The Leadership Quarterly, 9, 55-84.

Zaccaro, S. J. (2001). The nature of executive leadership: A conceptual and empirical analysis of success. Washington, DC: American Psychological Association.

Zaccaro, S. J. (2007). Trait-based perspectives of leadership. American Psychologist, 62, 6-16.

Zaccaro, S. J., Foti, R. J., \& Kenny, D. A. (1991). Self-monitoring and trait-based variance in leadership: An investigation of leader flexibility across multiple group situations. Journal of Applied Psychology, 76, 308-315.

Zaleznik, A. (1992, March/April). Managers and leaders: Are they different? Harvard Business Review, 126-133.

Zyphur, M. J., Narayanan, J., Koh, G., \& Koh, D. (2009). Testosterone-status mismatch lowers collective efficacy in groups: Evidence from a slope-as-predictor multilevel structural equation model. Organizational Behavior and Human Decision Processes, 110, 70-77. 